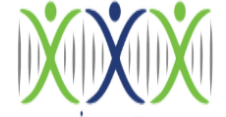

iRASD
Pakistan Journal of Humanities and Social Sciences

Volume 9, Number 3, 2021, Pages 460-468

Journal Homepage:

https://journals.internationalrasd.org/index.php/pjhss

\title{
Relationship between Body Image Dissatisfaction and Social Media Usage in Young Women
}

\author{
Ahmad Bilal ${ }^{1}$, Sehrish Wazir ${ }^{2}$, Bushra Farooq ${ }^{3}$ \\ ${ }^{1}$ Assistant Professor, Department of Applied Psychology, The Islamia University of Bahawalpur, Pakistan. \\ Email: ahmadbilal4@gmail.com \\ ${ }^{2}$ Lecturer, Department of Applied Psychology, Government Sadiq College Women University, Bahawalpur, Pakistan. \\ Email: sehrishwazir15@gmail.com \\ ${ }^{3}$ Research Scholar, Department of Applied Psychology, The Islamia University of Bahawalpur, Pakistan. \\ Email: bushraf268@gmail.com
}

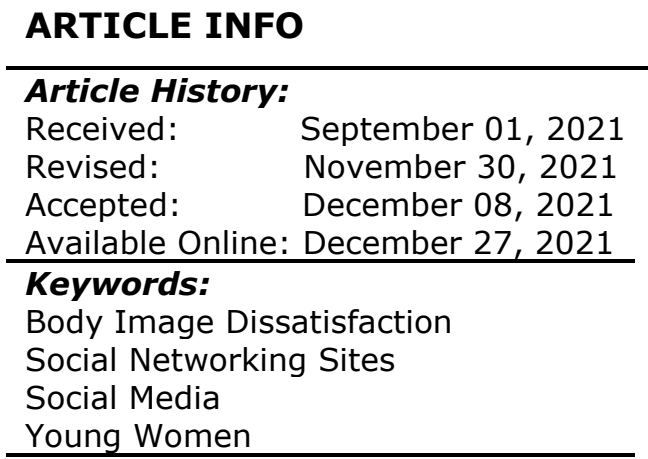

\section{ABSTRACT}

Young women have been found to experience body image dissatisfaction as a consequence of excessive social media usage and vice versa. Therefore, the current study was conducted to examine the relationship between body image dissatisfaction and social media use in young women aged 19-23 years in a Pakistani sample. A sample of 401 young women from different cities of Punjab province completed an online Google Formbased questionnaire containing informed consent, demographic sheet, and two scales namely social networking usage scale and socio-cultural attitude towards appearance questionnaire-4 (SATAQ-4). The findings of the study significantly predicted excessive social media usage from body dissatisfaction. The pressure sub scale of body image dissatisfaction was found to be significantly associated with social media usage. There were found no differences in body image dissatisfaction and social media usage in single and married young women. However, urban women were found to have high levels of body image dissatisfaction than rural women. The study concluded that body image dissatisfaction could lead to excessive social media usage in young women. The future directions and limitations of the study were discussed.

(c) 2021 The Authors, Published by iRASD. This is an Open Access Article under the Creative Common Attribution Non-Commercial 4.0

Corresponding Author's Email: ahmadbilal4@gmail.com

\section{Introduction}

Exposure to the media is cited as a reason for the development of dissatisfaction with the body or negative thoughts and feelings towards the body (Grogan, 2017). While eating disorders most frequently occur in late teens (19-23 years), risk factors predict the onset of eating disorders in earlier times appear and rise during teens (Rohde et al., 2015). Previous studies have shown that adolescent body dissatisfaction is a strong and consistent forecast of future symptoms of eating disorders (Grogan, 2017; Rhode et al., 2015). Exposition and sensitivity to media images that reflect idealized and unrealistic cultural standards are greatly affected by body dissatisfaction. For this reason, it is important that the risk factors contributing to the development of female dissatisfaction and malnutrition are understood for future interventions, especially in connection with heavy media use, the symptom understanding of body dissatisfaction and eating disorders during adolescence. The intersection of social, psychological and physical changes characterizes adolescence as a development period. Women avoid groups of same-sex friends throughout their childhood and want to communicate more with their opposite sexes and engage in romantic activities (Connolly \& McIsaac, 2009). The development of status hierarchies in and between social groups creates more complexity among peer groups (Brown \& Larson, 2009).

Merriam Webster (2014) defines social media as a way to share the information, ideas, personal messages, and other content in an online community (as social networking and 
micro-blogging web sites), through which users can create online community (as videos). While the term was first used in 2004, the use of social media went up over the last few years. This 10 -year-old sentence is now a family term. People seem to be more connected than ever, whether it's tweeting in real time during a bachelor party or creating a Facebook profile for their cat. Today, approximately $73 \%$ of adult online users use some type of social media (Smith et al., 2013).

Body image is a multifaceted construct that refers to an individual's thoughts, feelings, and behaviors associated with their body and physical appearance (Cash, 2002). Physical dissatisfaction refers to negative perceptions of body shape and weight (Stice et al., 1994). It is worth noting that young women in Western society have a high degree of dissatisfaction with their bodies, so they are often referred to as "normative dissatisfaction." (Tiggemann, 2011). In a recent survey of Australians, almost half of young women (18-29 years) reported being dissatisfied with their appearance. Body dissatisfaction has been consistently implicated in the etiology and maintenance of eating disorders, obesity, low self-esteem, depression, unhealthy dieting, excessive exercise, and cosmetic surgery. Given the prevalence of dissatisfaction with the body and its harmful effects, most studies so far have focused on negative body image and its influencing factors (Cash \& Smolak, 2011). However, in the past ten years, body image literature has surpassed the mainstream focus. A more comprehensive investigation into the construction of positive body image is through changes in body image (Halliwell, 2015). Positive body image is defined as a structure different from negative body image, including love, respect, acceptance and appreciation of one's own image. Importantly, positive body image is related to variables other than physical satisfaction, such as better mental health and adaptive health behaviors (Andrew et al., 2015; Swami \& Tovee, 2009). Accordingly, leading researchers in the field have argued that further research into positive body image may be crucial for prevention and treatment efforts aimed at improving body image (Tylka, 2011) and disordered eating (Cook-Cottone, 2015; Piran, 2015), by encouraging a focus on psychological and physical well-being in addition to preventing pathology.

\section{Literature Review}

Theories focusing on risk factors for dissatisfaction usually highlight developmental and socio-cultural factors (Heinberg \& Thompson, 1995). Developmental theories of body picture dissatisfaction highlight the importance of late body picture formation in children's and adolescent developmental factors, such as pubertal timing, overweight, early sexual abuse (Heinberg \& Thompson, 1995). In contrast, sociocultural image dissatisfaction theories address the influence of factors such as socio-cultural ideals, mass media influence and gender-based socialization in body image development (Heinberg \& Thompson, 1995). The following subset of potential risk factors for body image dissatisfaction in college women had been examined in the wide range of variables with the potential for negative effects: a) developmental teasing, (b) a history of childhood and adolescent excess weight, (c) the present weight or body mass index and $(d)$ the perceived influence of media on appeal.

Although the objectification idea approaches are the end result of the complicated socio-cultural surroundings wherein ladies live, the mass media have acquired a huge percentage of blame for growing and selling the ultra-skinny sort of frame this is presently appeared as 'ideal' with the aid of using Pakistani cultures. Correlational and experimental research had been achieved to hyperlink the publicity of thinness-depicting media with the massive un-fulfillment of the lady frame, extended funding in look and extended aid for disordered consuming behavior (Grabe et al., 2008).

Research has begun to examine the relationship between social media and corporate images with the recent proliferation of social networking (SNS). SNS, such as Facebook and Instagram are websites which enable quick sharing of photos, videos and comments generated by users through their personal profiles (Perloff, 2014). Facebook has more than 2.4 billion users, and Instagram has more than one billion users with more than 95 million photos every day sharing only on Instagram (Anderson \& Jiang, 2018). SNS like Facebook or Instagram, with over 80 percent of women aged 18-29 who use Facebook and more than $60 \%$ who use Instagram, is especially popular with young women (Anderson \& Jiang, 2018). SNS was described as a dominant way in which people perceive social standards. Research suggests that younger girls spend plenty extra time on on-line media than on conventional kinds of media inclusive of magazines and TV (Bair et al., 2012). SNS are predominantly peer 
generated, they offer sufficient possibility for comparisons with comparable others (Fardouly \& Vartanian, 2015). SNS are generated primarily by peers and offer ample opportunity to compare appearance to similar others (Fardouly \& Vartanian, 2015). A content analysis of the inspiration in the common photo sharing SNS found that pictures tend to be sexually objectivizing, focusing on ultra-thin women (a combination of the terms "thin" and 'inspiration') (Ghaznavi \& Taylor, 2015). Furthermore, evaluation of the textual content accompanying those pictures found out that customers generally tend to evaluate bodies with the skinny-perfect pictures displaying a preference to be skinny for perfection, to sense disgusted with fat, to benefit weight (Ghaznavi \& Taylor, 2015; Tiggemann \& Zaccardo, 2016).

There are several gaps in the literature regarding the relationship between social media use and young women's body image. First, the use of SNS has been regarded as homogeneous to date and most studies have generally measured total use of SNS, typically using one item, measuring the time spent with SNS. In fact, since SNS use is heterogeneous and involves both active involvement and passive consumption, the overall evaluation of time of use can mask significant effects. A modern approach is required to measure SNS use, especially appearancefocused work, to provide an important insight into the effects of body image Second, they commented in the suggestions of Prieler and Choi (2014) that most research to date has focused on young populations to broaden the scope of corporate image study in connection with social media effects and that future research would investigate age groups other than women. Statistics on the use of social media show that young adults (18-29) are the highest social media users, in particular young women (Anderson \& Jiang, 2018). Similarly, the 'positive body' trend in social media is emerging which is designed to encourage positive physical images. This kind of content needs to be studied in order to better understand how exposure to social media's "body positiveness" can influence body image in comparison with more dominant look-ideal contents.

Therefore, the present study was conducted with an aim to find out the association between social media use and body image dissatisfaction. The study also aimed to find out the demographics as related to social media use and body image dissatisfaction in young women. The hypotheses of the Study are given below;

H1: The sub-scales of body image dissatisfaction are positively correlated with social network usage.

H2: The body image dissatisfaction predicts and leads to high social network usage.

H3: The unmarried persons have high body image dissatisfaction and social network usage than married people.

H4: The urban living persons have high body image dissatisfaction and social network usage than rural people.

\section{Method}

\subsection{Research Design \& Participants}

The cross sectional survey method was used in this study to collect data. A total of 401 females were selected for the study from the different cities of Punjab through purposive sampling. The sample size was calculated using Raosoft online sample size calculator with $95 \%$ confidence interval and $5 \%$ margin of error.

\subsection{Instruments}

\subsubsection{Demographic Sheet}

This sheet comprises of the respondent name (optional), age, marital status and residential area.

\subsubsection{Social Networking Usage Scale (SNS)}

The SNS usage scale was designed (Gupta \& Bashir, 2018) to assess the four numbers of domains, including academic; socialization; entertainment; and informativeness. It has a total number of 19 items that are assessed on a 5-point scale (Always $=5$, Often $=4$, Sometimes $=3$, Rarely $=2$, and Never $=1$ ) indicating whether they feel pressure toward or away from a number of activities and to what degree. The current SNS alpha scale of Cronbach $(a=.83)$ therefore shows good internal reliability. 


\subsubsection{Sociocultural Attitudes towards Appearance Questionnaire-4 (SATAQ-4)}

The SATAQ-4 has 22 items that use a Likert-type scale from 1 to 5, ranging from "completely disagree" to "completely agree". These items are divided into five domains or subscales: Two are for internalization that have 5 items each. Within the internalization of the ideal of thinness, the desire to have a body with little body fat is measured. Within the internalization of the athletic ideal, the desire to have a muscular and toned body is measured. Likewise, the three are pressure subscales having 4 items each, which assess the pressure exerted by family, friends, and the media to have a slim and toned body in each of the subscales. The original version of SATAQ-4 shows a high internal consistency in the population where it was applied (university women), having a Cronbach's alpha for the global scale of 0.93, and a Cronbach's alpha between 0.88 and 0.97 for each of the domains (Llorente et al., 2015).

\subsection{Procedure}

The permission was taken from the author of questionnaire to use questionnaire in research. The questionnaire containing demographic sheet and two scales was distributed through social media platforms such as Facebook and WhatsApp. The data was analyzed through Statistical Package for Social Sciences (SPSS 25.0). The correlation, linear regression, and independent sample t-test, were used to test the hypotheses. The ethical considerations were maintained.

\section{Results}

The Table 1 gives the frequency distribution of demographic variables included in the study. The mean age of the participants was around 21 years with 19 and 23 years as the minimum and maximum age. The $81 \%$ participants were unmarried while $88 \%$ participants lived in urban areas.

Table 1: Frequency Distribution of Demographic Variables $(n=401)$

\begin{tabular}{cccc}
\hline Demographic Variables & Characteristics & $\boldsymbol{n}$ & \% \\
\hline Marital Status & Married & 75 & 18.7 \\
& Unmarried & 326 & 81.3 \\
Residential Area & Urban & 354 & 88.3 \\
& Rural & 47 & 11.7 \\
\hline \multirow{2}{*}{ Age (years) } & M (SD) & Min & Max \\
\hline
\end{tabular}

Table 2: Correlations among Body image dissatisfaction scale and social network Usage $(n=401)$

\begin{tabular}{cccccccc}
\hline Variables & $\mathbf{M}$ & SD & $\mathbf{1}$ & $\mathbf{2}$ & $\mathbf{3}$ & $\mathbf{4}$ & $\mathbf{5}$ \\
\hline Internalize-General Scale & 25.57 & 6.13 & - & & & \\
Athletic Scale & 6.68 & 1.92 & $.56^{* *}$ & - & & \\
Pressure Scale & 22.13 & 5.01 & $.68^{* *}$ & $.64^{* *}$ & - & & \\
Info Scale & 17.18 & 3.04 & $.59 * *$ & $.35^{* *}$ & $.47^{* *}$ & - & \\
SNU & 44.52 & 9.99 & -.09 & -.04 & $-.13^{* *}$ & -.07 & - \\
\hline
\end{tabular}

$* * p<.01$, Note. SNU=Social network usage

The Table 2 describes the correlations for testing a relationship among body image dissatisfaction sub-scales and social network usage. There is a statistically significant relationship among all sub scales of body image dissatisfaction. On the other hand, only pressure scale is negatively and significantly correlated with social network usage.

Table 3: Multiple Linear Regression $(n=401)$

\begin{tabular}{cccccccc}
\hline Predictors & $\mathbf{R}^{\mathbf{2}}$ & $\mathbf{F}(\mathbf{d f})$ & $\mathbf{S i g}$. & $\boldsymbol{\beta}$ & $\mathbf{S E}$ & $\mathbf{T}$ & Sig. \\
\hline $\begin{array}{c}\text { Internalize-General Scale } \\
\text { Athletic Scale }\end{array}$ & & & & -.01 & .12 & -.17 & .85 \\
$\begin{array}{c}\text { Pressure Scale } \\
\text { Info Scale }\end{array}$ & .02 & \multirow{2}{*}{$2.39(4,396)$} & .05 & .08 & .34 & 1.27 & .20 \\
& & & & -.17 & .15 & -2.31 & .02 \\
& & & & .01 & .20 & -.27 & .78 \\
\hline
\end{tabular}

Outcome=SNU; Predictors $=$ Scales of body image dissatisfaction 
The Table 3 gives the regression analysis to predict social network usage from body image dissatisfaction. The overall regression model was not found statistically significant. Only, the pressure sub scale significantly predicted social network usage.

Table 4: Result of $t$ Test $(n=401)$

\begin{tabular}{|c|c|c|c|c|c|c|c|}
\hline \multirow{2}{*}{ Marital Status } & \multicolumn{2}{|c|}{$\begin{array}{l}\text { Married } \\
(n=75)\end{array}$} & \multicolumn{2}{|c|}{$\begin{array}{c}\text { Unmarried } \\
(n=326)\end{array}$} & \multirow[t]{2}{*}{$t$} & \multirow[t]{2}{*}{ df } & \multirow{2}{*}{ Sig. } \\
\hline & $M$ & SD & $M$ & SD & & & \\
\hline $\begin{array}{c}\text { Internalize-General } \\
\text { Scale }\end{array}$ & 27.22 & 6.30 & 26.42 & 6.09 & 1.01 & 399 & .31 \\
\hline Athletic Scale & 6.81 & 1.47 & 6.65 & 2.01 & .77 & 144.79 & .44 \\
\hline Pressure Scale & 22.58 & 4.57 & 22.02 & 5.11 & .86 & 399 & .38 \\
\hline Info Scale & 17.29 & 3.47 & 17.15 & 2.94 & .30 & 99.70 & .75 \\
\hline SNU & 44.61 & 9.11 & 44.50 & 10.19 & .08 & 399 & .93 \\
\hline
\end{tabular}

The Table 4 gives the results of $t$ test computed to find out marital status differences in body image dissatisfaction and social network usage. The results of t test are not statistically significant. There are no marital status wise differences in body dissatisfaction and social network usage.

Table 5: Result of $t$ Test $(n=401)$

\begin{tabular}{cccccccc}
\hline \multirow{2}{*}{ Residential Area } & \multicolumn{2}{c}{ Urban $(\mathbf{n = 3 5 4})$} & \multicolumn{2}{c}{ Rural $(\mathbf{n = 4 7})$} & \multirow{2}{*}{$\boldsymbol{*}$} & \multirow{2}{*}{ df } & \multirow{2}{*}{ Sig. } \\
\cline { 2 - 5 } & $\mathbf{M}$ & $\mathbf{S D}$ & $\mathbf{M}$ & $\mathbf{S D}$ & & & \\
\hline Internalize-General Scale & 27.07 & 5.99 & 22.85 & 5.95 & 4.54 & 399 & .000 \\
Athletic Scale & 6.77 & 1.90 & 6.00 & 1.95 & 2.62 & 399 & .009 \\
Pressure Scale & 22.35 & 4.91 & 20.46 & 5.50 & 2.43 & 399 & .001 \\
Info Scale & 17.36 & 2.97 & 15.80 & 3.20 & 3.34 & 99.70 & .001 \\
SNU & 44.09 & 9.65 & 47.72 & 11.91 & -2.00 & 54.31 & .005 \\
\hline
\end{tabular}

The Table 5 gives the results of $t$ test computed to find out residential area differences in body image dissatisfaction and social network usage. The results of $t$ test are statistically significant for all scales of body image dissatisfaction whereas results are not significant for social network usage. The urban people have high levels of body image dissatisfaction than rural people.

\section{Discussion}

The current study aimed to examine the association between body image dissatisfaction and social media usage and to predict the increased social media use from body image dissatisfaction in young women. After the data analysis, results showed that greater number of unmarried respondents participated in the study compared to married respondents. Higher number of participants from urban areas participated as compared to respondents of rural areas.

The first hypothesis of the study "the sub-scales of body image dissatisfaction are positively correlated with social network usage". The results of the study reveal that the sub scales of body dissatisfaction are positively correlated with each other but the pressure sub scale is only correlated with social media usage. The social media platforms were the most difficult platforms with regard to the negative results of body images as compared to other platforms such as print media. This was consistent with the negative appearance-related outcomes of a previous study that indicated that time spent on social media led to a higher tendency to experience body image concerns like face, hair and skin-related discontent (Fardouly et al., 2015; Jiotsa et al., 2021).

Dissatisfaction with the body, negative thoughts, and feelings about one's appearance are a form of negative self-esteem (Kim \& Aubrey, 2015). The main purpose of this study was to investigate the extent to which the use of social media was associated with the different aspects of body dissatisfaction. The heavy use of social media platforms, excessive internalization and excessive-searching social comparisons boom the opportunity of dissatisfaction with the body. The effects additionally display that low shallowness will increase 
self-criticism, which ends up in greater dissatisfaction together along with your body (Fardouly et al., 2018; Sagioglou \& Greitemeyer, 2014).

The second hypothesis of the study was "dissatisfaction with the body image forecasts and leads to high social network utilization." The study results showed that body discontent poses a substantial threat to the well-being of women by increasing the odds of using social media usage (Stice \& Bearman, 2001). In order to counteract dissatisfaction with the body, it is important to know which factors are related to women's dissatisfaction with the body. Studies have shown that women who use social media are more likely to show greater dissatisfaction with their bodies (Holland \& Tiggemann, 2016). Women have a stronger connection between social media and physical dissatisfaction (Kleemans et al., 2018). Current research focuses on the individual characteristics of susceptibility to social media dissatisfaction with the body and examines the inhibitory effects of social environmental factors (Ridgway \& Clayton, 2016). As a preceding study (Holland \& Tiggemann, 2016) and a socio-cultural model (Thompson et al., 1999), it is shown that ladies who use social media regularly have a more effect on their bodies which is simply dissatisfaction.

The third hypothesis of the study was "the unmarried persons have high body image dissatisfaction and social network usage than married people". The results of t test for computing differences was not statistically significant. There were found no marital status wise differences in body dissatisfaction and social network usage. Both the single and married women were found to be equally effected by body image dissatisfaction and social media usage. This was consistent with a previous study (de Varies et al., 2016). The younger and single ladies who use social media have a tendency to be extra disillusioned with their bodies. This locating is constant with the truth that energetic social media customers are extra disillusioned with their bodies (Fardouly \& Vartanian 2015; Schaefer et al., 2014; Thompson et al. 1999).

The fourth hypothesis of the study was "the urban living women have high body image dissatisfaction and social network usage than rural people". The results of t test computed to find out residential area differences in body image dissatisfaction and social network usage revealed statistically significant difference for all scales of body image dissatisfaction whereas results were not significant for social network usage. The urban women have high levels of body image dissatisfaction than rural women. Understanding the susceptibility factors and situational factors related to the dissatisfaction of young women's body is essential to reduce the risk of dissatisfaction with body image and other related issues (Eke et al., 2014). Spending extra time on social media systems can result in needless self-criticism, which could result in a loss of satisfaction.

\section{Conclusion and Recommendations}

This research shows that social media is a new way to involve people in inappropriate processes, such as comparing body types in a targeted way. The study concluded that excessive dissatisfaction with one's body led to excessive social media usage. Demographics such as living in urban area could affect body dissatisfaction in young women.

The further research need to focus on finding out the higher-risk social media platforms based on the results of body imaging and prevent the use of these specific platforms. Moreover, future research should measure the processes that promote social media addiction in order to better clarify the meditation processes that influence attitudes and behavioral outcomes. The effective control measures should be developed to reduce user participation in inappropriate social media usage so that its negative effects could be mitigated. The social media platforms can be a good place for future health communication and behavior change activities to reach particularly vulnerable people in a positive way.

\section{Limitations}

This study did not assess whether users actually followed the processes that prompted them to use social media when using social media, such as company comparison. The user is an important factor to consider. Other reasons not investigated in this study (social support, identity establishment, social influence, popularity, etc.) should also be investigated. More research is needed to understand why users have different social media motivations and how to promote responsive applications on social media to reduce the harmful effects of improper 465 
use. Likewise, more research is needed to determine the impact of positive/protective processes (such as social support) and social media, and then maintain these processes to offset the negative impact of these processes.

\section{References}

Anderson, M., \& Jiang, J. (2018, Nov 28). Teens and their experiences on social media. Pew Research Center. https://www.pewresearch.org/internet/2018/11/28/teens-and-theirexperiences-on-social-media/

Andrew, R., Tiggemann, M., \& Clark, L. (2015). The protective role of body appreciation against media-induced body dissatisfaction. Body Image, 15, 98-104. https://doi. org/ 10.1016/j.bodyim.2015.07.005

Bair, C. E., Kelly, N. R., Serdar, K. L., \& Mazzeo, S. E. (2012). Does the Internet function like magazines? An exploration of image-focused media, eating pathology, and body dissatisfaction. Eating Behaviors, 13, 398-401. http://dx.doi. org/ 10. 1016/j.eatbeh.2012.06.003

Brown, B. B., \& Larson, J. (2009). Peer relationships in adolescence. In R. M. Lerner \& L. Steinberg (Eds.), Handbook of adolescent psychology (3rd ed., pp. 75-103). Hoboken, NJ: John Wiley \& Sons.

Cash, T. F., Fleming, E. C., Alindogan, J., Steadman, L., \& Whitehead, A. (2002). Beyond body image as a trait: The development and validation of the Body Image States Scale. Eating Disorders, 10, 103-113.

Cash, T. F., \& Smolak, L. (Eds.). (2011). Body image: A handbook of science, practice, and prevention (2nd ed.). The Guilford Press.

Connolly, J., \& McIsaac, C. (2009). Romantic relationships in adolescence. In Handbook of Adolescent Psychology.

Cook-Cottone, C. (2015). Embodied self-regulation and mindful self-care in the prevention of eating disorders. Eating Disorders. DOI: 10.1080/10640266.2015.1118954

de Vries, D. A., Peter, J., de Graaf, H., \& Nikken, P. (2016). Female' social network site use, peer appearance-related feedback, and body dissatisfaction: Testing a mediation model. Journal of Youth and Adolescence, 45, 211-224.

Eke, H., N., Omekwu, C., O.,\& Odoh, J., N. (2014). The Use of Social Networking Sites among the Undergraduate Students of University of Nigeria, Nsukka. Library Philosophy and Practice (e-journal). 1195

Fardouly, J., Diedrichs, P. C., Vartanian, L. R., \& Halliwell, E. (2015). Social comparisons on social media: The impact of Facebook on young women's body image concerns and mood. Body Image, 13, 38-45. http://dx.doi.org/10.1016/i. bodyim.2014.12.002

Fardouly, J., \& Vartanian, L. R. (2015). Negative comparisons about one's appearance mediate the relationship between Facebook usage and body image concerns. Body Image, 12, 82-88. http://dx.doi.org/10.1016/j.bodyim.2014.10.004

Fardouly, J., Willburger, B., Vartanian, L.R. (2018). Instagram use and young women's body image concerns and self-objectification: Testing mediational pathways. New Media Soc, 20, 1380-1395. doi: 10.1177/1461444817694499

Ghaznavi, J., \& Taylor, L. D. (2015). Bones, body parts, and sex appeal: An analysis of \#thinspiration images on popular social media. Body Image, 14, 54-61.

Grabe, S., Ward, L. M., \& Hyde, J. S. (2008). The role of the media in body image concerns among women: A meta analysis of experimental and correlational studies. Psychological Bulletin, 134 (3), 460-476.

Grogan, S. (2017). Body image: Understanding body dissatisfaction in men, women and children (Third ed.).

Gupta, S., \& Bashir, L. (2018). Social networking usage questionnaire: Development and validation in an Indian higher education context. Turkish Online Journal of Distance Education, 19 (4), 214-227.

Halliwell E. (2015). Future directions for positive body image research. Body image, 14, 177189. https://doi.org/10.1016/j.bodyim.2015.03.003

Heinberg, L. J., \& Thompson, J. K. (1995). Body image and televised images of thinness and attractiveness: A controlled laboratory investigation. Journal of Social and Clinical Psychology, 14(4), 325-338. https://doi.org/10.1521/iscp.1995.14.4.325

Holland, G., \& Tiggemann, M. (2016). A systematic review of the impact of the use of social networking sites on body image and disordered eating outcomes. Body Image, 17, 100110. http://dx.doi.org/10.1016/j.bodyim.2016.02.008 
Jiotsa, B., Naccache, B., Duval, M., Rocher, B., \& Grall-Bronnec, M. (2021). Social Media Use and Body Image Disorders: Association between Frequency of Comparing One's Own Physical Appearance to That of People Being Followed on Social Media and Body Dissatisfaction and Drive for Thinness. International journal of environmental research and public health, 18(6), 2880. https://doi.org/10.3390/ijerph18062880

Kim, K. B., \& Aubrey, J. S. (2015). A cross-cultural comparison of cognitive and affective mediators in the relationship between media use and body image disturbance: focusing on US and Korean women. Asian Journal of Communication, 25(5), 507-524. http://doi.org/10.1080/01292986.2014.995681

Kleemans, M., Daalmans, S., Carbaat, I., \& Anschütz, D. (2018) Picture Perfect: The Direct Effect of Manipulated Instagram Photos on Body Image in Adolescent Girls. Media Psychology, 21(1), 93-110. DOI: 10.1080/15213269.2016.1257392

Llorente, E., Gleaves, D. H., Warren, C. S., Pérez-de- Eulate, L., \& Rakhkovskaya, L. (2015). Translation and validation of a spanish version of the sociocultural attitudes towards appearance questionnaire-4 (SATAQ-4). International Journal of Eating Disorders, $48(2), 170-175$.

Merriam, W. (2014). http://merriam-webster.com

Piran, N. (2015). New possibilities in the prevention of eating disorders: The introduction of positive body image measures. Body image, 14, 146-157. https://doi.org/10.1016/j.bodyim.2015.03.008

Perloff, R. M. (2014). Social media effects on young women's body image concerns: Theoretical perspectives and an agenda for research. Sex Roles: A Journal of Research, 71(11-12), 363-377. https://doi.org/10.1007/s11199-014-0384-6

Prieler, M., \& Choi, J. (2014). Broadening the Scope of Social Media Effect Research on Body Image Concerns. Sex Roles, 71, 378-388. https://doi.org/10.1007/s11199-014-0406-4

Ridgway, J.L., \& Clayton, R.B. (2016). Instagram unfiltered: Exploring associations of body image satisfaction, instagram \#selfie posting, and negative romantic relationship outcomes. Cyberpsychology Behavior and Social Network, 19, 2-7.

Rohde, P., Stice, E., \& Marti, C. N. (2015). Development and predictive effects of eating disorder risk factors during adolescence: Implications for prevention efforts. The International journal of eating disorders, 48(2), 187-198. https://doi.org/10.1002/eat.22270

Sagioglou, C., \& Greitemeyer, T. (2014). Facebook's emotional consequences: Why facebook causes a decrease in mood and why people still use it. Computers in Human Behavior, 35 , 359. doi:10.1016/j.chb.2014.03.003

Schaefer, L. M., Burke, N. L., Thompson, J. K., Dedrick, R. F., Heinberg, L. J., Calogero, R. M., (2014). Development and Validation of the Sociocultural Attitudes towards Appearance Questionnaire-4 (SATAQ-4). Psychological Assessment. 170-5.

Smith, A. R., Hames, J. L., \& Joiner, T. E., Jr. (2013). Status update: Maladaptive Facebook usage predicts increases in body dissatisfaction and bulimic symptoms. Journal of Affective Disorders, 149, 235-240. doi: $10.1016 /$ j.jad.2013.01.032

Stice, E., \& Bearman, S. K. (2001). Body-image and eating disturbances prospectively predict increases in depressive symptoms in adolescent girls: a growth curve analysis. Developmental psychology, 37(5), 597-607. https://doi.org/10.1037//00121649.37.5.597

Stice, E., Schupak-Neuberg, E., Shaw, H. E., \& Stein, R. I. (1994). Relation of media exposure to eating disorder symptomatology: An examination of mediating mechanisms. Journal of Abnormal Psychology, 103(4), 836. doi:10.1037/0021-843X.103.4.836

Swami, V., \& Tove'e, M. J. (2009). A comparison of body dissatisfaction, body appreciation, and media influences between street-dancers and non-dancers. Body Image, 6, 304307.

Thompson, J. K., Heinberg, L. J., Altabe, M. N., \& Tantleff-Dunn, S. (1999). Exacting beauty: Theory, assessment, and treatment of body image disturbance. Washington, DC: American Psychological Association.

Tiggemann, M. (2011). Sociocultural perspectives on human appearance and body image. In Cash, T. F., Smolak, L. (Eds.), Body image: A handbook of science, practice, and prevention (pp. 12-19). New York, NY: Guilford. 
Tiggemann, M., \& Zaccardo, M. (2016). 'Strong is the new skinny': A content analysis of \#fitspiration images on Instagram. Journal of Health Psychology. https://doi. org/ 10. $1177 / 1359105316639436$

Tylka, T. L. (2011). Positive psychology perspectives on positive body image. In T. F. Cash \& L. Smolak (Eds.), Body image: A handbook of science, practice, and prevention (2nd ed., pp. 56-64). New York, NY: Guilford Press. 